\title{
Penerapan Metode ELECTRE II Dalam Menentukan Faktor Yang Mempengaruhi Prestasi Belajar Mahasiswa Untuk Meningkatkan Nilai IPK
}

\author{
Nurinda Utari Damanik ${ }^{1}$, Poningsih ${ }^{2}$, Irawan $^{3}$ \\ ${ }^{1}$ Mahasiswa Program Studi Sistem Informasi, STIKOM Tunas Bangsa, Pematangsiantar \\ ${ }^{2}$ AMIK Tunas Bangsa, Pematangsiantar \\ ${ }^{3}$ STIKOM Tunas Bangsa, Pematangsiantar \\ nurindautaridamanik@gmail.com
}

\begin{abstract}
One of the goals of the teaching and learning process is changes in behavior both aspects of knowledge (cognitive), attitude (effective), and psychomotor aspects. Learning achievement achieved by students is essentialy a reflection of learning efforts. In general, the better the learning effort, the better the achievement will be, of course this is inseparable from the factor that influnce it, among others, motivation of parents' level of education, ways of learning taught by lecturers, concentration. Hower most students lack learning achievement so the IPK value decreases. Whereas if the IPK is high the it will be very easy to determine the job. Student learning achievement and to increase the IPK is strongly influenced by a factor for that it requires a study to increase the value of I. Realizedby making a decision support system in determining the factors that influence student achievement to increase the IPK score.
\end{abstract}

Keywords: DSS, ELECTRE II, Achievement, IPK value Taxpayers

\begin{abstract}
Abstrak
Salah satu tujuan proses belajar mengajar adalah perubahan tingkah laku baik aspek pengetahuan (kognitif), sikap (efektif), maupun aspek psikomotorik.Prestasi belajar yang dicapai oleh mahasiswa pada hakikatnya merupakan pencerminan dari usaha belajar.Pada umumnya semakin baik usaha belajar maka semakin baik pula prestasi yang akan dicapai,tentunya hal ini tidak terlepas dari faktor-faktor yang mempengaruhinya antara lain motivasi tingkat pendidikan orang tua, cara belajar yang diajarkan dosen, konsentrasi belajar dan etos kerja.Akan tetapi kebanyakan mahasiswa kurang dalam prestasi belajar sehingga nilai IPK menurun.Padahal jika IPK nya tinggi maka akan sangat mudah menentukan pekerjaan, prestasi belajar mahasiswa dan untuk meningkatkan nilai IPK sangat dipengaruhi oleh suatu faktor untuk itu diperlukan suatu penelitian untuk meningkatkan nilai IPK. Diwujudkan dengan pembuatan suatu Sistem Pendukung Keputusan dalam menentukan Faktor-faktor yang Mempengaruhi Prestasi Belajar Mahasiswa untuk Meningkatkan Nilai IPK.
\end{abstract}

Kata kunci: SPK, ELECTRE II, Prestasi, Nilai IPK

\section{Pendahuluan}

Proses belajar mengajar yang efisien sangat berpengaruh terhadap tingkat keberhasilan mahasiswa yang dinyatakan dengan prestasi belajar. Prestasi belajar merupakan hasil penilaian kemampuan, keterampilan yang dipelajari selama masa belajar untuk meningkatkan proses belajar mahasiswa. Faktor-faktor yang mempengaruhi prestasi belajar mahasiswa faktor yang bersifat situsional, maka perlu dilakukan optimalisasi. Optimalisasi prestasi belajar mahasiswa dapat dilakukan dengan mengkaji apa saja yang mempengaruhi prestasi belajar mahasiswa. Penyelenggaraan pendidikan tinggi perlu dilakukan melalui proses belajar di kelas. Proses belajar mengajar terkadang tidak berjalan sesuai dengan apa 
yang diharapkan, banyak faktor yang mempengaruhi prestasi belajar mahasiwa, misalnya faktor dosen, sarana dan prasarana, mahasiswa, metode pembelajaran, media yang tersedia serta faktor lingkungan yang kurang mendukung.

Untuk meningkatkan prestasi belajar mahasiswa peranan dosen sangat penting selain sebagai model dan teladan bagi mahasiswanya juga sebagai pengelola pembelajaran yang ditentukan oleh kualitas dan kemampuan dosen. Keberhasilan mahasiswa dalam proses belajar juga dipengaruhi oleh faktor internal dan eksternal. Faktor internal berasal dari dalam diri mahasiswa berupa bakat, kemampuan, perhatian dan motivasi. Faktor eksternal berasal dari lingkungan perguruan tinggi berupa tujuan belajar, materi pelajaran, interaksi antara mahasiwa dan dosen, interaksi mahasiswa dan materi dan mahasiwa dengan lingkungan. Disini penulis memberikan solusi dalam menentukan factor yang mempengaruhi prestasi belajar mahasiswa untuk meningkatkan nilai IPK. Agar membantu para dosen dalam menyampaikan materi pelajaran sesuai dengan kekurangan mahasiswa tersebut agar hasil materi pelajaran didapatkan nilai yang maksimal. ELECTRE II dapat digunakan untuk merangkingkan alternatif faktor yang mempengaruhi prestasi belajar mahasiswa untuk meningkatkan nilai IPK.

\section{Metode Penelitian}

\subsection{Sistem Pendukung Keputusan}

Sistem pendukung keputusan merupakan sistem informasi interaktif yang menyediakan informasi, pemodelan, dan pemanipulasian data [3]. Sistem pendukung keputusan merupakan resources individu secara intelek dengan kemampuan komputer guna meningkatkan kualitasi keputusan dan bisa sebagai manajemen pengambilan keputusan [4]. Sistem pendukung keputusan ditujukan untuk pengambilan keputusan yang bersifat analistis dalam situasi yang tidak terstruktur dan dengan kriteria yang kurang jelas.

\subsection{Indeks Prestasi Kumulatif}

IPK atau Indeks Prestasi Kumulatif merupakan keseluruan hasil nilai yang didapat mahasiswa dari semester yang telah dilalui. Semakin besar angka yang diperoleh mahasiswa maka semakin baik prestasi akademik yang mereka ukir. Hasil nilai yang didapat bisa berubah-ubah sesuai dengan faktor-faktor yang mempengaruhinya. Faktorfaktor tersebut antara lain faktor dari dalam (internal), faktor dari luar (external), faktorfaktor itulah yang nantinya akan memperkuat atau memperlemah Hasil nilai IPK. Salah satu alternatif untuk memecahkan masalah penurunan nilai IPK adalah membentuk suatu Organisasi atau kelompok belajar yang dapat membantu membangkitkan minat Mahasiswa dalam belajar.

\section{Hasil Pembahasan}

Metode yang digunakan dalam penelitian ini merupakan salah satu metode Sistem Pendukung Keputusan (SPK) yaitu ELECTRE II. Metode ELECTRE adalah sebuah metode yang menganalisis kebijakan yang melibatkan kriteria kualitatif dan kuantitatif. Yang mana menggunakan tipe kriteria yang sederhana yaitu nilai threshold-nya sama untuk semua kriteria sedangkan versi yang lain menggunakan pseudo criteria yang nilai threshold-nya tidak sama untuk semua kriteria [1][2][3].

Tabel 1. Data Alternatif

\begin{tabular}{ccccccccccc}
\hline Alternatif & \multicolumn{10}{c}{ Kriteria } \\
\cline { 2 - 12 } & C1 & C2 & C3 & C4 & C5 & C6 & C7 & C8 & C9 & C10 \\
\hline A1 & 4,33 & 4 & 4 & 4,67 & 4 & 4 & 4,33 & 4 & 4 & 4 \\
A2 & 5 & 4 & 3,67 & 4,33 & 5 & 4,67 & 5 & 4,33 & 3,67 & 4 \\
A3 & 5 & 5 & 3 & 4,50 & 5 & 4 & 4,50 & 4 & 4 & 4 \\
\hline
\end{tabular}




\begin{tabular}{crrrrrrrrrr}
\hline Alternatif & \multicolumn{10}{c}{ Kriteria } \\
\cline { 2 - 11 } & C1 & C2 & C3 & C4 & C5 & C6 & C7 & C8 & C9 & C10 \\
\hline A4 & 5 & 4,50 & 4 & 4 & 4,50 & 4,50 & 4 & 3,50 & 4 & 4 \\
\hline
\end{tabular}

\begin{tabular}{ccccccccccc}
\hline Alternatif & \multicolumn{10}{c}{ Kriteria } \\
\cline { 2 - 11 } & C11 & C12 & C13 & C14 & C15 & C16 & C17 & C18 & C19 & C20 \\
\hline A1 & 4,33 & 4,33 & 5 & 3,67 & 3,33 & 3 & 4 & 4,33 & 3,67 & 4,33 \\
A2 & 4 & 4,33 & 4 & 3,67 & 3 & 4 & 3,67 & 4,33 & 3,33 & 4 \\
A3 & 4 & 5 & 4 & 3 & 4 & 5 & 4 & 4 & 4 & 3,5 \\
A4 & 4 & 3 & 4 & 2 & 4 & 4 & 4 & 4 & 4 & 4 \\
\hline
\end{tabular}

Langkah-langkah metode ELECTRE II

a) Normalisasi matrik keputusan dapat dilakukan dengan persamaan :

$r i j=\frac{X_{\mathrm{i}_{j}}}{\sqrt{\sum_{\mathrm{i}=1}^{m} X_{\mathrm{i}_{j}}^{2}}}$

$X_{1}=\sqrt{(4,33)^{2}+(5)^{2}+(5)^{2}+(5)^{2}}=9,68$

$r_{11}=\frac{4 \mathrm{ag}}{9,52}=0,4472$

$r_{21}=\frac{5}{9.52}=0,5164$

$r_{21}=\frac{5}{9.52}=0,5164$

$v_{41}=\frac{5}{9,52}=0,5164$

$\mathrm{X}_{2}=\sqrt{(4)^{2}+(4)^{2}+(5)^{2}+(4,50)^{2}}=8,79$

$r_{12}=\frac{4}{8.79}=0,4551$

$r_{22}=\frac{4}{8.79}=0,4551$

$r_{\mathrm{a} 2}=\frac{5}{\mathrm{~g}, 79}=0,5689$

$r_{42}=\frac{4,50}{8,79}=0,5120$

Tabel 2. Normalisasi Nilai Matriks

\begin{tabular}{ccccccrrrr}
\hline $\mathbf{C 1}$ & $\mathbf{C 2}$ & $\mathbf{C 3}$ & $\mathbf{C 4}$ & $\mathbf{C 5}$ & $\mathbf{C 6}$ & $\mathbf{C 7}$ & $\mathbf{C 8}$ & $\mathbf{C 9}$ & $\mathbf{C 1 0}$ \\
\hline 0,4472 & 0,4551 & 0,542 & 0,5329 & 0,4307 & 0,4506 & 0,4841 & 0,504 & 0,5102 & 0,5 \\
0,5164 & 0,4551 & 0,4973 & 0,4941 & 0,5384 & 0,5261 & 0,559 & 0,5455 & 0,4681 & 0,5 \\
0,5164 & 0,5689 & 0,4066 & 0,5135 & 0,5384 & 0,4506 & 0,5031 & 0,504 & 0,5102 & 0,5 \\
0,5164 & 0,512 & 0,542 & 0,4564 & 0,4845 & 0,5632 & 0,4472 & 0,441 & 0,5102 & 0,5 \\
\hline \multicolumn{1}{c}{} & & & & & & & & \\
\hline $\mathbf{C 1 1}$ & $\mathbf{C 1 2}$ & $\mathbf{C 1 3}$ & $\mathbf{C 1 4}$ & $\mathbf{C 1 5}$ & $\mathbf{C 1 6}$ & $\mathbf{C 1 7}$ & $\mathbf{C 1 8}$ & $\mathbf{C 1 9}$ & $\mathbf{C 2 0}$ \\
\hline 0,53 & 0,5121 & 0,5852 & 0,5807 & 0,4614 & 0,3693 & 0,5102 & 0,5194 & 0,488 & 0,5455 \\
0,4896 & 0,5121 & 0,4682 & 0,5807 & 0,4157 & 0,4929 & 0,4681 & 0,5194 & 0,4428 & 0,504 \\
0,4896 & 0,5913 & 0,4682 & 0,4747 & 0,5542 & 0,6155 & 0,5102 & 0,4798 & 0,5319 & 0,441 \\
0,4896 & 0,3548 & 0,4682 & 0,3165 & 0,5542 & 0,4924 & 0,5102 & 0,4798 & 0,5319 & 0,504 \\
\hline
\end{tabular}

b) Pembobotan pada matriks yang telah dinormalisasi Matriks $\mathrm{V}$ merupakan hasil perkalian $\mathrm{R}$ dengan $\mathrm{W}$ (bobot), dimana w(bobot) dapat dilihat pada tabel 3

Tabel 3. Matriks Setelah Dinormalisasikan $\left(\mathrm{R}^{*} \mathrm{w}\right)$

\begin{tabular}{cccrrrcccc}
\hline $\mathbf{A 1}$ & $\mathbf{A 2}$ & $\mathbf{A 3}$ & \multicolumn{1}{c}{$\mathbf{A 4}$} & \multicolumn{1}{c}{$\mathbf{A 5}$} & $\mathbf{A 6}$ & $\mathbf{A 7}$ & $\mathbf{A 8}$ & $\mathbf{A 9}$ & $\mathbf{A 1 0}$ \\
\hline 0,0426 & 0,0412 & 0,0465 & 0,0431 & 0,0328 & 0,0322 & 0,0323 & 0,0312 & 0,0292 & 0,0262 \\
0,0492 & 0,0412 & 0,0426 & 0,04 & 0,041 & 0,0376 & 0,0373 & 0,0338 & 0,0267 & 0,0262 \\
0,0492 & 0,0515 & 0,0348 & 0,0416 & 0,041 & 0,0322 & 0,0335 & 0,0312 & 0,0292 & 0,0262 \\
0,0492 & 0,0463 & 0,0465 & 0,0369 & 0,0369 & 0,0402 & 0,0298 & 0,0273 & 0,0292 & 0,0262 \\
\hline
\end{tabular}




\begin{tabular}{rccccccccc}
\hline \multicolumn{1}{c}{$\mathbf{A 1 1}$} & $\mathbf{A 1 2}$ & $\mathbf{A 1 3}$ & $\mathbf{A 1 4}$ & $\mathbf{A 1 5}$ & $\mathbf{A 1 6}$ & $\mathbf{A 1 7}$ & $\mathbf{A 1 8}$ & $\mathbf{A 1 9}$ & $\mathbf{A 2 0}$ \\
\hline 0,025 & 0,0219 & 0,0223 & 0,0194 & 0,0132 & 0,0088 & 0,0097 & 0,0074 & 0,0046 & 0,0026 \\
0,0233 & 0,0219 & 0,0178 & 0,0195 & 0,0119 & 0,0117 & 0,0089 & 0,0074 & 0,0042 & 0,0024 \\
0,0233 & 0,0253 & 0,0178 & 0,0158 & 0,0158 & 0,0147 & 0,0097 & 0,0069 & 0,0051 & 0,0021 \\
0,0233 & 0,0152 & 0,0178 & 0,0105 & 0,0158 & 0,0117 & 0,0097 & 0,0069 & 0,0051 & 0,0024 \\
\hline
\end{tabular}

c) Menentukan himpunan Concordance dan Discordance index.

1) Himpunan Concordance, sebagai berikut:

$$
\begin{aligned}
& C k l=\{j, V k l \geq V i j\} C 12= \\
& \mathrm{V} 11 \geq \mathrm{V} 21=0,0426 \geq 0,0492 \\
& \mathrm{~V} 12 \geq \mathrm{V} 22=0,0412 \geq 0,0412 \\
& \mathrm{~V} 13 \geq \mathrm{V} 23=0,0465 \geq 0,0426 \\
& \mathrm{~V} 14 \geq \mathrm{V} 24=0,0431 \geq 0,0
\end{aligned}
$$

Dan seterusnya hingga $C 43$ sehingga didapatkan himpunan Concordance nya.

Kemudian nenghitung matriks Concordance, menggunakan persamaan, sebagai berikut :

$$
\begin{aligned}
& \mathrm{Ckl}=\sum j c w W j \\
& \begin{aligned}
C 12 & =w 1+w 2+w 3+w 4+w 6+w 7+w 9+w 13+w 14+w 16+w 17+w 18+w 20 \\
& =0,0952+0,0905+0,0857+0,0810+0,0714+0,0667+0,0571+0,0381 \\
& +0,0333+0,0238+0,0190+0,0143+0,0048=0,6800
\end{aligned}
\end{aligned}
$$

dan seterusnya hingga C43. Nilai dari komponen matriks disusun berdasarkan himpunan Concordance dengan bobot (W) dan dijumlahkan, sehingga menghasilkan matriks Concordance sebagai berikut:

Tabel 4. Matriks Concordance

\begin{tabular}{lcccc}
\hline Concordance & $\mathbf{A 1}$ & $\mathbf{A 2}$ & $\mathbf{A 3}$ & $\mathbf{A 4}$ \\
\hline $\mathbf{A 1}$ & - & 0,6048 & 0,5667 & 0,6048 \\
$\mathbf{A 2}$ & 0,6286 & - & 0,6476 & 0,6381 \\
$\mathbf{A 3}$ & 0,6952 & 0,6619 & - & 0,8381 \\
$\mathbf{A 4}$ & 0,6095 & 0,6238 & 0,5238 & - \\
\hline
\end{tabular}

2) Himpunan Discordance menggunakan persamaan sebagai berikut :

$$
\begin{aligned}
& D k l=\{j, V k l<V i j \\
& \mathrm{D} 12= \\
& \mathrm{V} 11 \geq \mathrm{V} 21=0,0426 \geq 0,0492 \\
& \mathrm{~V} 12 \geq \mathrm{V} 22=0,0412 \geq 0,0412 \\
& \mathrm{~V} 13 \geq \mathrm{V} 23=0,0465 \geq 0,0426
\end{aligned}
$$

Dan seterusnya hingga D43 sehingga didapat himpunan discordancenya.

Untuk menghitung nilai dari elemen pada matriks discordance adalah dengan membagi maksimum selisih nilai kriteria yang termasuk dalam subset discordance dengan maksimum selisih nilai seluruh kriteria yang ada, secara matematisnya seperti pada persamaan, sebagai berikut :

$D k l=\frac{\{\max (V m n-V m n-1 \mathrm{n})\} ; m, n € d k l v}{\left\{\max (V m n-V l n 1\} ; m, n=1,2,3_{s, m}\right.}$ 


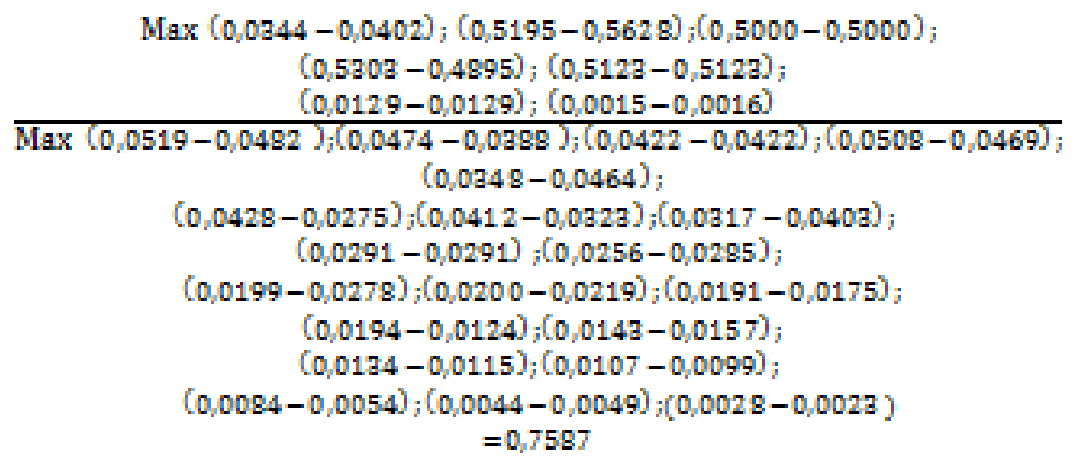

Dan seterusnya sampai D43, Sehingga diperoleh matriks discordance sebagai berikut:

Tabel 5. Matriks Discordance

\begin{tabular}{lcccc}
\hline Discordance & A1 & A2 & A3 & A4 \\
\hline C1 & - & 1 & 0,8864 & 0,9134 \\
C2 & 0,5435 & - & 1 & 0,5843 \\
C3 & 1 & 0,7559 & - & 1 \\
C4 & 1 & 1 & 0,8728 & - \\
\hline
\end{tabular}

d) Menentukan matriks dominan Concordance dan discordance.

Matriks dominan Concordance, Menghitung matriks dominan Concordance Threshold didapat dari penjumlahan seluruh elemen matriks dibagi ukuran matriks yang terdapat pada persamaan sebagai berikut :

$\frac{C^{*}=\sum n k=1 \sum n i=1}{\operatorname{Cklm} *(\mathrm{~m}-1)}$

Dan nilai setiap elemen matriks $f$ sebagai matriks dominan Concordance ditentukan sbb :

$$
\mathrm{f}_{\mathrm{kl}}=1, \text { jika } \mathrm{c}_{\mathrm{kl}} \geq \mathrm{c}^{\prime} \text { dan } \mathrm{f}_{\mathrm{kl}}=0, \text { jika } \mathrm{c}_{\mathrm{kl}}<\mathrm{c}^{\prime}
$$

Sehingga matriks dominannya adalah:

Tabel 6. Matriks Concordance

\begin{tabular}{ccccc}
\hline Dominan Concordance & A1 & A2 & A3 & A4 \\
\hline A1 & - & 0 & 0 & 0 \\
A2 & 0 & - & 1 & 1 \\
A3 & 1 & 1 & - & 1 \\
A4 & 0 & 0 & 0 & - \\
\hline
\end{tabular}

Matriks dominan discordance, Menghitung matriks dominan Discordance Threshold didapat dari penjumlahan seluruh elemen matriks dibagi ukuran matriks yang terdapat pada persamaan berikut:

$$
\frac{\mathrm{d}^{\mathrm{p}}=\sum \mathrm{nk}=1 \sum \mathrm{n} \mathrm{i}=1 \mathrm{Dkl}}{\mathrm{m} *(\mathrm{~m}-1)}
$$

Dan nilai setiap elemen untuk matriks g sebagai matriks dominan discordance ditentukan sebagai berikut :

Sehingga matriks dominannya adalah:

$$
\mathrm{g}_{\mathrm{kl}}=0, \text { jika d } \mathrm{d}_{\mathrm{kl}} \geq \mathrm{d}^{\prime} \text { dan } \mathrm{g}=1, \text { jika d } \mathrm{d}_{\mathrm{kl}}<\mathrm{d}^{\prime}
$$

Tabel 7. Matriks Dominan Discordance

\begin{tabular}{ccrrr}
\hline Dominan Discordance & A1 & A2 & A3 & A4 \\
\hline A1 & - & 1 & 1 & 1 \\
A2 & 0 & - & 1 & 0 \\
\hline
\end{tabular}




\begin{tabular}{crrrr}
\hline Dominan Discordance & A1 & A2 & A3 & A4 \\
\hline A3 & 1 & 0 & - & 1 \\
A4 & 1 & 1 & 0 & - \\
\hline
\end{tabular}

e) Menghitung indeks Concordance murni dan Discordance murni.

Concordance murni, untuk mencari nilai Concordance murni dapat dilihat pada persamaan berikut :

$$
\begin{aligned}
& C j=\sum n k=1 c(j, k)-\sum n k=1 C(k, j),(j \neq k) \\
& C 1=0,6048+0,5667+0,064-(0,6206+0,6952+0,6095)=-0,6898 \\
& C 2=0,6206+0,6475+0,638-(0,6048+0,6619+0,6238)=0,0431 \\
& \text { C3 }=0,6925+0,6619+0,838-(0,5667+0,6475+0,5238)=0,4571 \\
& \text { C4 }=0,6095+0,6238+0,5238-(0,064+0,638+0,838)=0,2171
\end{aligned}
$$

Discordance murni, Untuk mencari nilai discordance murni dapat dilihat pada persamaan.

$$
\begin{aligned}
& D j=\sum n k=1 d(j, k)-\sum n k=1 d(k, j),(j \neq k) \\
& \text { D1 }=1+0,8864+0,9134-(0,5435+1+1)=0,2563 \\
& \text { D2 }=0,5435+1+0,5543-(1+0,7559+1)=0,6581 \\
& \text { D3 }=1+0,7559+1-(0,8864+1+0,8728=-0,6567 \\
& \text { D4 }=1+1+0,8728-(0,9134+0,5543+1)=0,4051
\end{aligned}
$$

Setelah kedua indeks telah dihitung, maka untuk mendapatkan alternatif terbaik adalah dengan mencari nilai rata rata dari kedua peringkat indeks Concordance murni dan Discordance murni. sehingga didapatkan peringkat peringkat sebagai berikut berdasarkan tabel 8 .

Tabel 8. Perhitungan Alternatif Terbaik

\begin{tabular}{ccccccc}
\hline Faktor & Corcodance & Rank & Discordance & Rank & $\begin{array}{c}\text { Averange } \\
\text { Rank }\end{array}$ & $\begin{array}{c}\text { Final } \\
\text { Rank }\end{array}$ \\
\hline A01 & 0,0238095238095236 & 2 & $-0,628100213323636$ & 4 & 3 & 1 \\
A02 & $-0,157142857142857$ & 3 & 0,2563108577737414 & 2 & 2,5 & 2 \\
A03 & $-0,323809523809524$ & 4 & 0,375062572685903 & 1 & 2,5 & 3 \\
A04 & 0,457142857142857 & 1 & 0,003227093709968196 & 3 & 2 & 4 \\
\hline
\end{tabular}

Berdasarkan tabel 8 diatas dapat diambil keputusan bahwa A02 menjadi faktor yang mempengaruhi prestasi belajar mahasiswa untuk meningkatkan nilai IPK dimana alternatif A02 adalah Materi Pelajaran, dengan average terbesar yaitu 2,5.

f) Keluaran (Output) Sistem

Matriks A memberikan urutan pilihan alternatif dari setiap alternatif yaitu bila A1 $=1$ maka alternatif yang lebih baik dari A1 sehingga matriks dalam baris matriks A yang memiliki A1 = 1 paling sedikit dapat di eleminasi dan yang memiliki A1 paling banyak merupakan alternatif yang terbaik sehingga disimpulkan bahwa alternatif yang terbaik adalah A2 yaitu Materi Pelajaran dan dapat di lihat pada Sistem yang di bangun dan dikembangkan dengan menggunakan bahasa pemrograman PHP dan MySQL sebagai databasenya berikut: 


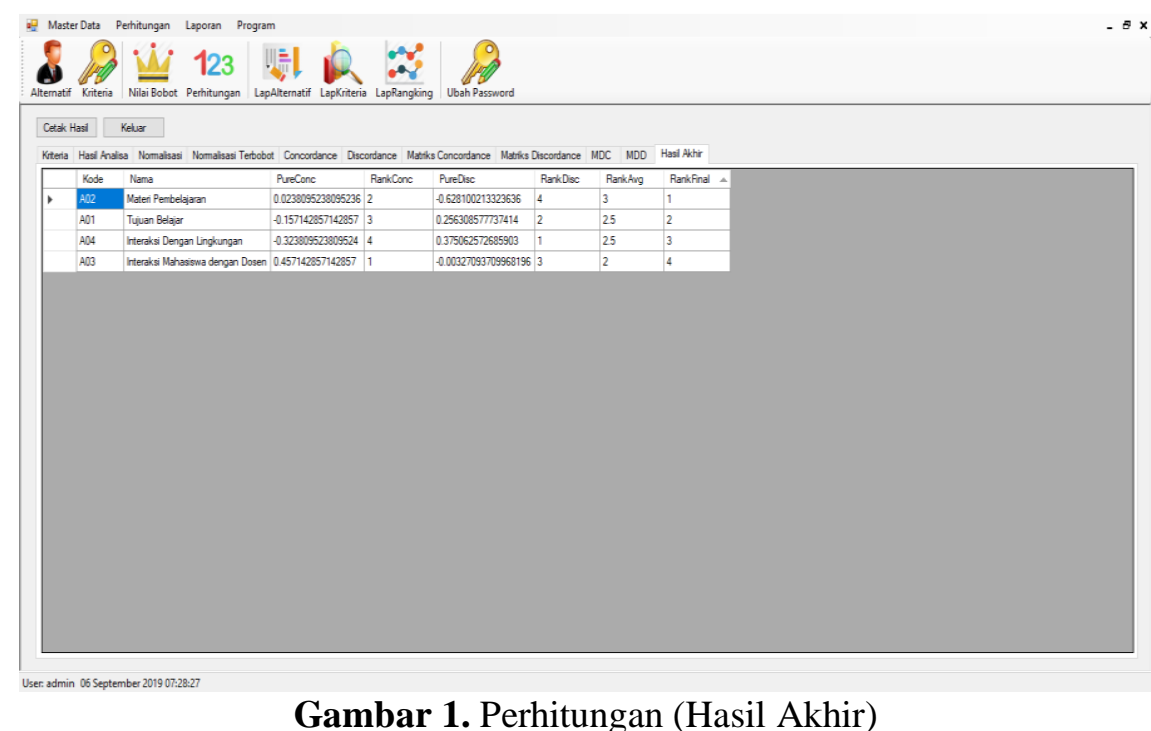

\section{Kesimpulan}

Berdasarkan hasil perhitungan sistem pendukung keputusan menggunakan metode ELECTRE II, maka peneliti menarik kesimpulan sebagai berikut:

a. Hasil penelitian yang diperoleh dapat disimpulkan bahwa perhitungan ELECTRE II dan aplikasi $v b$ net dapat digunakan untuk menentukan faktor utama yang mempengaruhi prestasi belajar mahasiswa untuk meningkatkan nilai IPK dengan menggunakan metode ELECTRE II. Dan dapat disimpulkan atau dilihat faktor utama yang mempengaruhi prestasi belajar mahasiswa untuk meningkatkan nilai IPK pada hasil akhir yaitu A02 dengan alternatif materi pelajaran.

b. Hasil yang diperoleh menggunakan sebuah metode yaitu ELECTRE II yang di uji menggunkan aplikasi $v b$ net. Dengan memasukan data hasil dari perhitungan manual ELECTRE II dan di simpulkan bahwa ELECTRE II adalah sebuah metode yang mudah untuk membuat suatu keputusan dalam pemilihan maupun perangkingan suatu permasalahan.

\section{Daftar Pustaka}

[1] L. P. Purba, A. P. Windarto, and A. Wanto, "Faktor Terbesar Rendahnya Minat Ber-KB (Keluarga Berencana) Dengan Metode ELECTRE II," pp. 369-374, 2018.

[2] S. Sundari et al., "Sistem Pendukung Keputusan Dengan Menggunakan Metode Electre Dalam Merekomendasikan Dosen Berprestasi Bidang Ilmu Komputer ( Study Kasus di AMIK \& STIKOM Tunas Bangsa)," no. x, pp. 1-6, 2017.

[3] S. R. Ningsih, I. S. Damanik, I. Gunawan, and W. Saputra, "Electre Dalam Menentukan Penerima Program Indonesia Pintar ( Pip ) Melalui Kartu Indonesia Pintar (KIP) (Studi Kasus: Sd Swasta Al - Washliyah Moho Kabupaten Simalungun)," vol. I, pp. 264-275, 2017.

[4] Y. Kristyawan and A. Rizeki, "Sistem Pendukung Keputusan Distribusi Rehabilitas Sosial Rumah Tidak Layak Huni pada Kab Sampang Menggunakan Metode Vikor," vol. 2, no. 1, pp. 1-8, 2017.

[5] Y. Primadasa and H. Juliansa, "Penerapan Metode Vikor dalam Seleksi Penerimaan Bonus Pada Salesman Indihome," pp. 33-43. 